\title{
Analysis of Causes of Delay and Time Performance in Construction Projects
}

\author{
Anita Rauzana \\ Department of Civil Engineering, Syiah Kuala University, Jl. SyechAbdurRauf, Banda Aceh, Aceh Province, \\ Indonesia
}

\begin{abstract}
The success of a construction project depends on the cooperation between the parties involved, namely the building owners, contractors and project planners. Many factors could hinder the implementation of construction projects. The success of carrying out construction projects on time without any obstructions in the implementation is one of the most important goals. Project construction experience obstacles and constraints in implementation is a condition that is very undesirable, because it would be very detrimental to all parties. Every construction project has a specific implementation plan, when the implementation of the project should begin, when to be solved and how it will carried out, and how the provision of resources. The problem will arise if there is no appropriateness between the plans that have been made with the actual reality. Problems that arise would be an obstacle to be avoided for the implementation of construction projects can proceed smoothly. The result showed that the main cause of the factors that affect delays in the completion of projects in Aceh Besar was social and cultural factor.
\end{abstract}

Keywords: constraints, project, contractor, delay

\section{Introduction}

Development is an attempt to create the prosperity and welfare. Therefore, the development should be benefited by all community as increased prosperity inner and outer with a fair and equitable manner. In line with the rapidity of physical development, then start up companies who work as implementers and planners for the construction of buildings, roads and irrigation. This is motivated by the expectations to get a big profit. The construction project is a mission, undertaken to create a unique facility, product or service within the specified scope, quality, time, and cost (Chitkara, K.K., 2004).

In the area of Aceh Besar, the development company specialized in the construction sector does not indicate the rate of decline. In fact, the implementation of physical projects always get the job constraints, both constraints are already calculated, as well as outside the calculation planner. Constraints it causes obstruction of the project work, so that the project work is not progressing according to plan. Therefore, in the implementation of a construction project there is always a possibility, that the time required to complete the project will exceed the allotted time in the contract documents. In other words, the project completion time is inhibited. The cause delays in the project, among others, issues of material, labor, equipment, finance, environment, and poor management. Delays in construction work would cause losses for both moral and material. Parties affected by such losses are directly related to the project which the contractor. The contractor will experience a loss of time and cost, because the gains expected by the contractor can be reduced, and did not reach the expected target. According to Bing et al. (2005), the uncertainty variables in construction projects are affected by macroeconomics of a country. In addition, the delay resulted in lost opportunity for other project work. For the owner, the delay in the completion of the project work will caused losses to the operating time of the results of the project, so that the use of the results of the development project was delayed. During project implementation, there are many uncertainty variables that dynamically affect duration of activity, and hence cost (Leu et al., 2001). Many uncertainties associated with international construction arise from differences in culture, economic conditions, specifications or standards, legal frameworks, and productivity levels (Dikmen\&Birgonul, 2006).

Contractors have undertaken on time, it would be beneficial to both parties. In order to obtain a position as a good corporate citizen and always timely in the completion of projects, always attempted a method to avoid delays in the construction business world. Various ways have been carried out by the construction companies to avoid delays in the completion of construction projects, for example, worked on the entire construction work, as well as empowering human resources.

Principal problem under studyareinhibiting factors in the completion of project construction could cause delays. Problem solving was conducted with the process and concludes the data obtained from the project has been done. In this study, the hypothesis is taken from the material and socio-cultural factors that become a major inhibiting factor in the completion of construction work in the field in Aceh Besar. The aims of 
researchare to identify the factors that could hinder the completion of the project, seeking the main factors affecting the delay completion of the project in Aceh Besar;

Limitation problems are:

a) The research locations in the area of Aceh Besar.

b) The factors thatcould hinder the work of construction projects in Aceh Besar.

c) Methods of data collection by way of questionnaires and interviews.

The benefits derived from this study are as consideration for company specialized in the construction field, especially in the field and for the Government of Aceh Besar in order to avoid delays in the project in the future.

\subsection{Construction Project}

\section{II. Literature Review}

According to Mulyani (2006), construction projectsare series of projects related to the construction field who have limited time dimension with specific allocation of resources, in order to realize an idea and a particular purpose, after the idea is feasible. To complete construction projects, have adhered to the boundary three obstacles are:

a) Budget, the construction project should be efficient.

b) Schedule, the construction projects to be effective.

c) The quality, performance must meet the required of specifications and criteria.

The main elements that are within a project:

a) Cost : finance and investment.

b) Quality: the size of the desired quality and obvious requirements.

c) Quantity: large or dimensions of the project.

d) Time: when and how long it takes for the implementation of the building.

In the normal construction projects must go through a long process and very complex. There is a series of sequential and related to a construction project activity. Series of activities consisting of planning, design stage, the stage of the procurement / the auction implementation phase, maintenance phase, and preparation for use. In general, the classification or type of construction projects can be divided into:

a) The project of building construction

b) The construction of housing / residential

c) Project construction civil engineering or heavy engineering construction projects

d) Project construction industry

\subsection{The Problems in Construction Project}

In essence, the way of handling the implementation of simple construction projects to the construction of mega-projects, each of which will establish a specific pattern management system, which is special. Nevertheless, the stages of the main activities in the process of construction of various types of projects tend to form a sort order that is similar to one another, may even be the same for some projects. The principal of activities is based on areas of expertise and the professions involved, whereas the sequence of stages arranged based on the specific conditions relating to the technical challenges and the need for a mechanism in the process, which further is attached to a main feature of the industry.

The problem faced in the process of the construction outline can be classified into two, namely:

a. Issues relating to the interdependence and influence are closely between cost, time and quality. Implementation of construction has always aimed to produce a quality result with financing money is not wasteful, and all of which should be available in a limited time span, given the large investment costs to be invested.

b. The issue that is highly correlated with the activities of coordination and control for all management functions. In the implementation of an activity involving the construction of the owners, consultants and contractors. In this case, they have their respective duties. Coordination between owners, consultants and contractors are necessary in order to the work can proceed smoothly and in accordance with the wishes of the previous.

\subsection{Project Delays}

Project delays can be caused from the contractor and is derived from the owner. Delays can also occur but is not caused by the two parties. Construction project delays mean additional implementation time 
completion of projects that have been planned and specified in the contract documents. Timely completion of the work is not a shortage of productivity levels, and will result in waste in financing, either in the form of direct financing is spent on government projects, as well as swelling of intangible investments and losses on private projects. According to Subramanian et al. (2012), the uncertainty that affect the time in construction projects is a factor of economic or market fluctuations that are not profitable.According Rauzana (2016), uncertainty factors that influence estimated time is inflation.

Delays in projects are often a source of disputes and claims between the owner and the contractor, so it would be very expensive in value, both in terms of the contractor and the owner. The contractor will be fined a penalty in accordance with the contract. In addition, contractors are also experiencing additional overhead cost for the project is still ongoing. In terms of owners, project delays will impact income reductions due to delay in the operation of its facilities. Delays in completion of the project can be avoided or reduced if the assessment project schedule well done. The active role of management is one of the key of successful management of the project.

\section{- Classification Construction Delays}

According to Scott (1997), a delay in project implementation can be classified into three things: a compensable delay, non-compensable delay, and concurrent delay. According to Popescu and Charoengam (1995), when seen based on its responsibility, the delay can be classified into excusable delay, non- excusable delay, and concurrent delay.

\section{- Identification of Construction Delays}

Prior to implementation of a project, is necessary to identify the risk factors that could affect the project time performance. These factors couldderived from the owner, the supervising consultant, and project implementers(contractors).According Praritama (1976), internal factors are the cause of the delay caused by the project implementers. In the construction phase, the project executor is a contractor. In the internal factor or factors of implementation, aspects that potentially caused the delay of which is a factor of materials, tools, labor, and management execution. External factors are factors of delays caused by parties outside of the executor of the project, but contribute directly on the construction project. The external factors include the delay caused by the owner, supervisors and planners.

- Impact of Delay

Delays in the project would be causing any losses on the part of the contractor, consultant and owner, namely:

a) The contractor

Delays in completion of the project resulting in the increase in overhead, increase the length of time for implementation. Overhead costs include costs for the company as a whole, regardless whether there is a contract that is being addressed.

b) The consultant

Consultants will experience a loss of time, and will delayed in doing other projects, if the project implementation has been delayed completion.

c) The owner

Project delays on the part of the owner, it means loss of income from the buildings which should already be used or rent. If the owner is the government, for public facilities such as hospitals would delay will be detrimental to public health services, or detrimental to the service program has been prepared. These losses can not be valued in money that can not be paid back. Meanwhile, if the owner is a non-government, such as the construction of buildings, shops, or hotel, of course the use of the building schedule will retreat from the planned time, so there is an empty time without getting any money.

\subsection{Data Collection}

\section{Research Methodology}

In this study, which is the respondentsarecontractors in Aceh Besar. The data obtained by a questionnaire data, namely distributing questionnaires and conducting interviews to 20 respondents are contractors. While secondary data are obtained from the Department of public works. The data in this study is quantitative data, i.e. data collected and processed to seek or obtain how much the inhibiting factors can affect the progress and delays in the completion of construction projects. Score each variable is as follows: 
- $\quad$ Very low Influence $=1$

- $\quad$ Medium Influence $=2$

- Influence $=3$

- $\quad$ Very influence $=4$

\subsection{Design of Questionnaire}

The questionnaire is a list of operational questions asked of respondents was selected to answer hypotheses developed according to the research objectives. A questionnaire was designed in three groups, namely:
a) Personal Data of
b) Data of project
c) Inhibiting factors, namely the points on the inhibiting factors in completing construction projects, namely:

1) The material factors:

A. Shortage of construction materials

B. The late delivery of materials

C. Damage to the material in storage

D. Scarcity because of the specificity

E. Inaccuracy time of reservation

2) Labor factor (manpower):

(A) Lack of labor

(B) The ability of labor

(C) The experience labor

3) Factors equipment:

(A) Damage to equipment

(B) Lack of equipment

(C) The late delivery of equipment

(D) The productivity of the equipment

4) Financial factors:

(A) Availability of finance for implementation

(B) The increase in the price of materials

5) Environmental factors:

(A) social and cultural factors

(B) The effect of weather on construction activity

(C) Effect of environmental safety of the project

6) Factors of change:

(A) Changes in the design by owner

(B) design errors made by planners

\subsection{Research DataProcessing}

After all data is obtained throughthe questionnaire collected, then do the next stage of data analysis. Data analysis using quantitative methods operated by using SPSS 21.0 for Windows, to find how many of the factors that affect the implementation of the project.

- Analysis of Respondents

Data presented by the respondent in the questionnaire that has been deployed, processed and used to provide a description or explanation.

- Analysis of Ranking

Mean is used to determine the factors that influence in the delay of the works construction projects Mean is obtained by summing the data of all individuals in the group, and then divided by the number of individuals in the group. This can be seen by the following formula: 
Where:

$$
M_{e}=\frac{\sum_{i=1}^{n} X_{i}}{n}
$$

$\mathrm{Me}=$ Mean

$\mathrm{n}=$ number of respondents

$\mathrm{Xi}=$ frequency at provided by the respondents, as a percentage of the number of respondents to each issue.

$\mathrm{i}=$ index categories of respondents $(\mathrm{i}=1,2,3, \ldots)$

$\mathrm{X} 1$ = frequency of answer "very influence"

$\mathrm{X} 2$ = frequency of answer "influence"

X3 = frequency ofanswer 'medium influence "

X4 = frequency of answer "very low influence".

\section{Results And Discussion}

Based on the research findings, it can be concluded that the key factor that constrain completion of construction projects in Aceh Besarwas social factor had mean value of 3.50 as a major inhibiting factor.In Indonesia, social and cultural life of a group of people is influenced by tribal customs and traditions. Customs and habits of the people will give birth to a culture that shapes and influences the character of its people. Indonesia is a country, which consists of various ethnicities, customs, and traditions that will provide behavioural and social or cultural difference. The results of this study are presented in Table 1.

Table 1. The results of the most influential factors of delay

\begin{tabular}{|l|l|l|}
\hline Delay Factor & Mean & Ranking \\
\hline Social and cultural factors & 3,77 & 1 \\
\hline
\end{tabular}

According toKalayjian(2000), uncertainty in construction projects is affected by social and cultural differences. According to Bing et al. (2005), uncertainty in construction projects is affected by social differences. For players who do not understand the construction of social behaviour or culture of the community around the project, will give a value of uncertainty.

\section{Conclusions}

In the implementation of the project, often occurs problems both technical and nontechnical the problem, in this study, the problem or a major inhibiting factor is the social factor. The social factor is the nontechnical factors in the implementation of the project. The problem that occurs is generally a disagreement between the government and the residents around the work site. In the road improvement project, often carried out the land acquisition process that requires a long time, this will effect on process of the project.

Not all residents immediately agreed conducted the land acquisition, but there are also people who take a long time to agreed to land acquisition by the government. Other social issues that arise in the process of implementation of the construction project is going on vehicle traffic problems surrounding residents. With the road construction, the traffic flow will be obstructed, jams, because there is in part of the road that is being done and can not be passed. Work on conditions of the densely populated area so that the flow of traffic in the area is very crowded. The presence of road project, it can close the pathways alley or housing complex to exit and enter the vehicle. The execution must be compatible tothe requests of citizens who asked for constructioncarried out at the times that are not crowded vehicles such as Friday, Saturday and Sunday are not a rush hour traffic flow, so that the implementation process can not be done every day.

\section{References}

[1]. Rauzana, A. (2016). The effect of the risk factors on the performance of contractors in Banda Aceh, Indonesia.ARPN Journal of Engineering and Applied Sciences, 11(15), 9496 - 9502.

[2]. Bing, L.,Akintoye, A., Edwards, P. J.,\&Hardcastle, C. (2005). The allocation of risk inPPP/PFI construction projects in the UK.International JournalProject Management, 23, 25-35.

[3]. Chitkara, K. K. (2004). Construction project management, planning, scheduling and controlling. New Delhi: Tata McGraw-Hill Publishing Company.

[4]. Dikmen, I., \&Birgonul, M. T. (2006). A review of international construction research: Ranko Bon's contribution. Journal Construction Management Economic, 24(7), 725-733. 
[5]. Kalayjian,W. H. (2000). Third world markets anticipating the risks: Civil engineering. Journal of Construction Engineering And Management,70(5), 56-59.

[6]. Leu, S. S., Chen, A. T., \& Yang, C. H. (2001). A GA-based optimal model for construction time-cost trade-off.International Journal Project Management, 19, 47-58.

[7]. Mulyani, E. (2006).Construction Management. Aceh Besar: FakultasTeknikUntan.

[8]. Popescu, C. M., \&Charoengam, C. (1995). Project Planning, Schedulling, and Control in Construction. Canada: John Willey \& Son, p.188.

[9]. Praritama. (1976). TindakanKorektfdanPreventifTerhadapSumberResiko yang MenyebabkanKeterlambatanpadaProyekKonstruksi Fly Over di Provinsi DKI Jakarta. (Unpublished master's thesis).

[10]. Scott, S. (1997). Delay Claims in UK Contracts. Journal of Construction Engineering and Management, Sept 1997, p.238.

[11]. Subramanyan, H., Sawant, P. H., \& Bhatt, V. (2012).Construction project risk assessment development of model based on investigation of opinion of construction project experts from India.Journal of Construction Engineering and Management,138(3), $409-421$ 